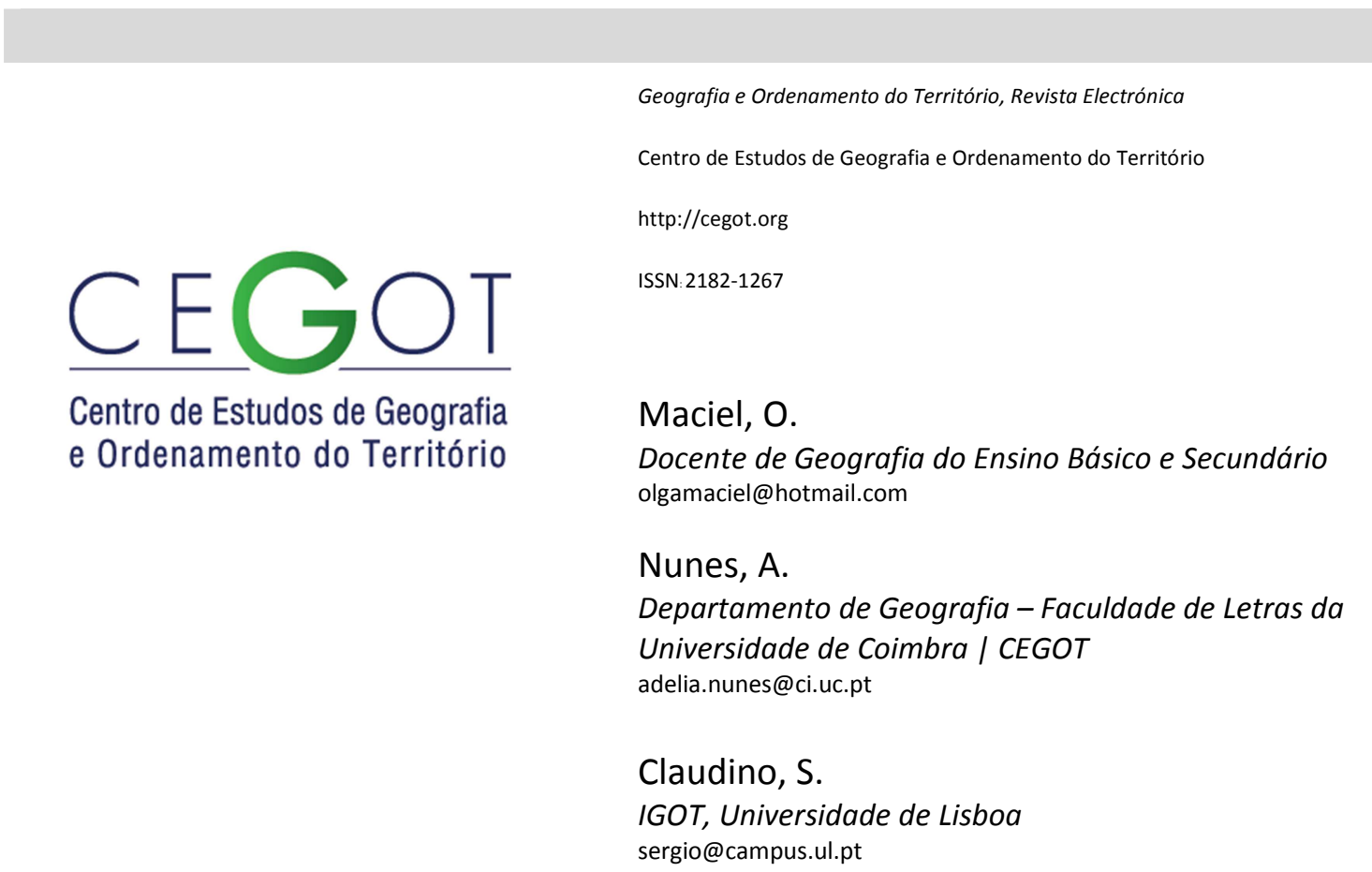

\title{
Recurso ao inquérito por questionário na avaliação do papel das Tecnologias de Informação Geográfica no ensino de Geografia
}

Referência: Maciel, O. et. al (2014). Recurso ao inquérito por questionário na avaliação do papel das Tecnologias de Informação Geográfica no ensino de Geografia. Revista de Geografia e Ordenamento do Território (GOT), n. 6 (dezembro). Centro de Estudos de Geografia e Ordenamento do Território, p. 153-177

\section{Resumo}

Com o presente artigo, pretende-se apresentar a metodologia usada na implementação de uma investigação baseada em inquérito por questionário. Este tem por principal objetivo identificar as representações dos docentes de Geografia do ensino básico e secundário (EBS) e dos professores formandos de História e Geografia sobre o papel das Tecnologias de Informação Geográfica (TIG) no ensino da disciplina de Geografia. Sistematizam-se os procedimentos metodológicos da técnica inquérito por questionário e coloca-se em evidência o modo como foi construído e aplicado o questionário "O papel das TIG no ensino de Geografia", desde a fase de definição de objetivos à implementação do processo de recolha de dados.

Palavras-Chave: inquérito, questionário, formulário eletrónico, docentes de Geografia, TIG 


\begin{abstract}
This article aims to discuss the methodology used in the implementation of a research based on a survey, which main goal is to unveil the vision of teachers of Geography, in service and pre-service condition, concerning the role of geotechnologies on teaching Geography. After the systematization of the methodological procedures, the work is focused on showing the way used to structure and apply the survey, from setting the objectives until the implementation of data collection.
\end{abstract}

Keywords: survey, web survey, Geography teachers, geotechnologies

\title{
1. 0 inquérito enquanto metodologia de investigação
}

De entre as diversas opções metodológicas no domínio da investigação em ciências sociais e humanas, o inquérito ou survey assume-se como sendo uma das de uso mais recorrente (Ferreira \& Campos, 2009).

A conceção e a implementação de um survey é um processo cujo objetivo é a recolha de informação temática válida e fiável, obtida a partir das respostas individuais dadas a um conjunto de questões por um grupo representativo de respondentes, em torno das quais se produzem conclusões passíveis de serem generalizadas ao universo da população em estudo (Thayer-Hart et al., 2010). Ghiglione \& Matalon (1995, p. 8) definem inquérito como sendo "uma interrogação particular acerca de uma situação, englobando indivíduos com o objetivo de generalizar". Segundo Coutinho (2011), e consoante os objetivos básicos que presidem ao inquérito (descrever/explicar/explorar comportamentos, atitudes, valores e situações), são diferenciáveis cinco tipos de surveys (descritivo, explicativo, exploratório, transversal e longitudinal), cujos limites na prática são, por vezes, ténues. Esta autora coloca a investigação por survey ao nível dos planos não experimentais ou descritivos.

O planeamento de um inquérito inicia-se muito antes do processo de inquirição propriamente dito (Fig. 1). A sua estruturação principia com a definição de uma problemática a que a investigação visa responder, a qual poderá ser enunciada através de uma pergunta de partida (Quivy \& Campenhoudt, 1998) ou norteada pela fixação de objetivos (Ghiglione \& Matalon, 1995). Em função das razões que previsivelmente explicitarão o fenómeno em estudo, são formuladas as hipóteses de investigação sujeitas a verificação (Coutinho, 2011). Ainda na fase de planeamento, é fundamental definir os conceitos ou constructos que se pretendem avaliar e proceder à sua operacionalização em 
variáveis. Sublinha-se que uma revisão bibliográfica consistente afigura-se como indispensável a um correto enquadramento da problemática que se pretende estudar.

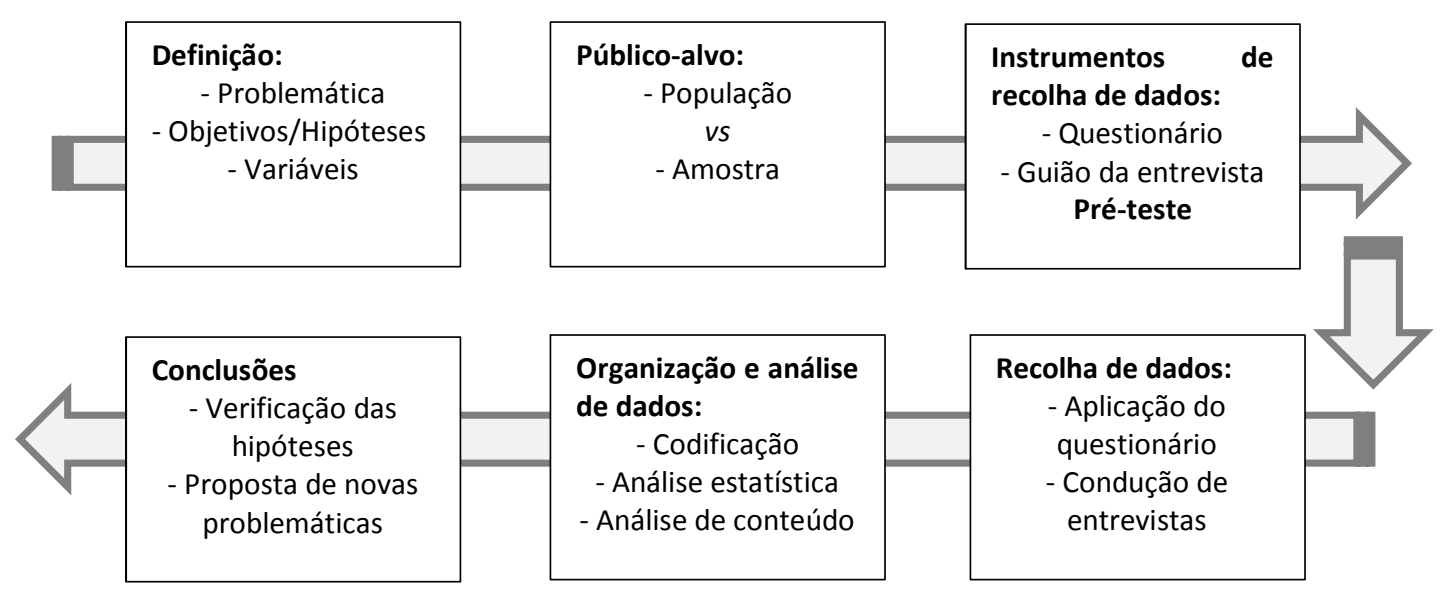

Figura 1 - Planeamento de um survey ou inquérito

Numa investigação por inquérito, o levantamento de dados pode ser conduzido através da realização de entrevistas (presenciais ou telefónicas) ou pela aplicação de um questionário (Coutinho, 2011). O processo de recolha de dados é complementado por métodos de análise de dados, os quais permitem organizar, apresentar e descrever os dados e abrem caminho à identificação de relações e padrões entre os elementos/variáveis. A análise estatística e a análise de conteúdo são dois referenciais para o tratamento de dados de um questionário e de entrevistas, respetivamente.

A análise de dados permite avançar para a interpretação dos factos, o estabelecimento de relações, esperadas ou não esperadas, e para a confirmação/revisão das hipóteses. Deste modo, na apresentação de conclusões o investigador pode "sugerir aperfeiçoamentos do seu modelo de análise ou propor pistas de reflexão e de investigação para o futuro" (Quivy e Campenhoudt, 1998: 211).

\subsection{O questionário enquanto técnica de inquirição}

Tendo em conta a modalidade de preenchimento do questionário, este pode ser de administração direta - o preenchimento fica a cargo do próprio respondente; ou de administração indireta - o inquiridor regista a informação fornecida pelo respondente (Quivy \& Campenhoudt, 1998: 188). Na primeira modalidade, também designada por 
questionário autoadministrado (Ghiglione \& Matalon, 1995), o instrumento tanto pode ser entregue em mão, como pode ser remetido por correio.

As novas tecnologias de informação ampliaram as modalidades de obtenção de dados. 0 uso do correio eletrónico para a distribuição de questionários remonta a 1985 (Sheehan, 2001) e está documentado desde 1996 o recurso a formulários web preenchidos on-line (Couper \& Miller, 2008). Desde então, a condução de surveys com recurso a formulários HTML, os web surveys, têm-se tornado prática comum, em particular em investigação educacional (Solomon, 2001). Em Portugal, o uso do inquérito por questionário na investigação em ensino de Geografia já se encontra documentado, quer em suporte papel, quer em suporte eletrónico (Esteves, 2010; Costa, 2011).

O recurso à administração de inquéritos por questionário, tal como qualquer outra modalidade de investigação, apresenta virtudes e constrangimentos. A possibilidade de auscultar um número significativo de indivíduos, acompanhada pela possibilidade de quantificar os dados obtidos e, consequentemente, proceder à sua análise estatística, contribuem para a popularidade dos questionários.

A condução de uma investigação através de inquérito por questionário revela algumas fragilidades. De acordo com Ghiglione \& Matalon (1995), Quivy \& Campenhoudt (1998) e Coutinho (2011), as limitações mais comuns prendem-se com os métodos de amostragem não aleatórios, dado que nestes casos não é possível garantir a representatividade dos indivíduos inquiridos, o que implica que as conclusões do estudo só se aplicam, em rigor, à amostra. Os elevados níveis de não resposta ao questionário (recusas, não retorno) podem fazer com que não se alcance o tamanho mínimo da amostra, enviesando-a. Por fim, a impossibilidade de estabelecer relações causais entre as variáveis restringe os resultados da investigação a uma descrição de dados.

Aos web surveys acrescem constrangimentos a que o investigador deve estar atento. A virtualização do contacto com o inquirido pressupõe equacionar aspetos técnicos relacionados com o acesso à tecnologia e com a compatibilidade do equipamento usado pelos respondentes (Reja et al., 2003).

O facto de o serviço de acesso à internet não ser universal constitui uma limitação base à realização de questionários on-line, suscetível de comprometer uma boa cobertura da 
população, facto que ameaça a representatividade da amostra quando se opta por métodos de inquirição probabilísticos, conduzidos através da internet (Couper, 2000; Lynn, 2013). Paralelamente, um menor grau de familiarização com as ferramentas da web por parte de alguns segmentos da população é perspetivado como um fator dissuasor do preenchimento do questionário on-line (Jeavons, 1998 apud Solomon, 2001). O receio de que seja seguido o rasto eletrónico do respondente é também referenciado como um fator de recusa do preenchimento de questionários on-line (Couper, 2000). Há ainda a referir que, em situações em que os contactos com os potenciais respondentes é feito por email, corre-se o risco de a mensagem ser bloqueada por processo de filtragem (Graeml \& Csillag, 2008).

Outro risco subjacente ao mundo virtual, e que se poderá repercutir negativamente nos resultados da investigação, prende-se com a falta de controlo do investigador sobre os reais respondentes (Lynn, 2013), correndo-se, por exemplo, o risco de haver submissão de múltiplas respostas por parte do mesmo indivíduo, o que pode originar amostras enviesadas (Solomon, 2001; Jansen et al., 2007). Ainda nas questões relacionadas com a segurança, há que ter em conta que o acesso ao inquérito on-line pode ser feito de forma acidental ou, até, maliciosa.

Como estratégias para minimizar as limitações, no campo da segurança, há algumas soluções técnicas que passam, por exemplo, pela distribuição de uma chave de acesso aos potenciais respondentes. Já em relação aos problemas de cobertura da população, estes podem ser ultrapassados com a limitação desta metodologia a populações onde está garantido o acesso à internet (Couper, 2000), visto que, tal como alerta Solomon (2001), existem populações específicas onde o acesso à internet é extremamente elevado, facto que releva para segundo plano a questão do enviesamento da cobertura da amostra. Todavia, nesta matéria, não existe consenso quanto à melhor estratégia para alcançar a representatividade da população e garantir a qualidade dos dados (Roberts, 2013; Nicolaas et al., 2014).

Ainda no âmbito das preocupações levantadas pelos questionários on-line, há que referir que diversos estudos apontam para uma menor taxa de resposta comparativamente às modalidades tradicionais de inquérito (Couper, 2000; Solomon; 2001; Nicolaas et al, 2014). Acresce ainda o facto de Sheehan (2001), ao analisar a evolução das taxas de resposta de 
inquéritos realizados por correio eletrónico, concluir que se tem verificado um decréscimo das taxas de resposta a este tipo de abordagem.

A abonar os web surveys, encontra-se o estudo realizado por Díaz De Rada \& DomínguezÁlvarez (2014) sobre a qualidade da informação extraída de inquéritos autoadministrados via web, no qual se demonstra que esta modalidade apresentou um menor número de questões não respondidas e respostas mais desenvolvidas nas questões abertas, comparativamente à modalidade em suporte de papel.

No campo das potencialidades dos web survey são apontados, essencialmente, fatores de ordem económica e de rapidez no processo de recolha de dados. Esta abordagem, por norma, traduz-se numa redução dos encargos financeiros da investigação, ao conceder a possibilidade de alcançar um grande número de potenciais respondentes sem grandes custos (Jansen et al, 2007; Lynn, 2013; Roberts, 2013). São também reconhecidas as maisvalias do inquérito on-line ao nível da simplificação do processo de registo dos dados (Jansen et al, 2007; Thayer-Hart et al, 2010; Roberts, 2013), considerando que estes são armazenados automaticamente numa base de dados, facto que concorre para uma diminuição do erro de digitação de informação (Solomon, 2001).

\section{O questionário "As TIG no ensino de Geografia"}

\subsection{Objetivos do questionário}

Conhecer a visão que os docentes de Geografia do Ensino Básico e Secundário (EBS), formandos e de carreira, têm em relação às Tecnologias de Informação Geográfica (TIG) constituiu o ponto de partida para a formulação do inquérito por questionário "As TIG no ensino de Geografia". Este objetivo geral assenta no princípio de que a disciplina de Geografia encontra nas TIG um importante recurso educativo. De referir que este pressuposto é corroborado pela "Rome Declaration on Geographical Education in Europe" (2013), documento que sublinha a relevância da utilização de informação geográfica e das tecnologias geoespaciais na educação geográfica. Outras premissas em torno das quais se estruturou o questionário foram que: 
- as TIG são reconhecidas pelos docentes de Geografia como ferramentas com potencialidades educativas, ajustadas aos objetivos do ensino, em geral, e da educação geográfica, em particular;

- fatores endógenos (grau de capacitação) e exógenos (organizacionais, infraestruturação tecnológica, curriculares) condicionam a integração das TIG nas práticas escolares dos professores de Geografia.

\subsection{População}

Por se ter considerado pertinente auscultar a comunidade de docentes e futuros docentes de Geografia relativamente ao papel das TIG enquanto ferramentas didáticas no processo de ensino-aprendizagem, definiu-se que estes dois conjuntos populacionais constituíam os públicos-alvo do inquérito por questionário "AS TIG no ensino de Geografia", aplicado no ano letivo de 2013/2014. Ressalva-se que, em relação aos futuros docentes de Geografia, o questionário restringiu-se aos alunos que frequentam o segundo ano do Mestrado em Ensino de História e de Geografia, dado que o seu percurso académico e a experiência formativa que estão a desenvolver os tornam melhores conhecedores da causa subjacente ao questionário.

Segundo os dados mais recentes publicados pela Direção-Geral de Estatísticas da Educação e Ciência do Ministério da Educação e Ciência (DGEEC \& DSEE, 2014), no ano letivo de 2012/2013 encontravam-se em exercício 4084 docentes de Geografia (3 682 no Ensino Público e 402 no Ensino Privado), maioritariamente do sexo feminino e distribuídos geograficamente de acordo com os dados do Quadro I. Apesar do desfasamento temporal em relação ao período de aplicação do inquérito, face à inexistência de dados mais atualizados, assume-se este valor como uma referência indicativa do universo populacional dos professores de Geografia em exercício.

Quadro I - Professores de Geografia do 3.o ciclo do ensino básico e do ensino secundário (EBS),

\begin{tabular}{|c|c|c|c|c|c|c|c|c|c|c|}
\hline \multirow{3}{*}{ 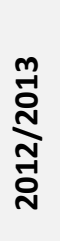 } & \multirow{2}{*}{ Total } & \multicolumn{2}{|c|}{ Género } & \multicolumn{7}{|c|}{ NUT II } \\
\hline & & M & $\mathbf{F}$ & Norte & Centro & Lisboa & Alentejo & Algarve & RAA & RAM \\
\hline & 4084 & $\begin{array}{c}1161 \\
(28,4 \%)\end{array}$ & $\begin{array}{c}2923 \\
(71,6 \%)\end{array}$ & 1411 & 863 & 1098 & 281 & 155 & 127 & 148 \\
\hline
\end{tabular}

Fonte: DGEEC \& DSEE, 2014 
Dos contactos estabelecidos com os coordenadores e alguns dos docentes dos cursos das instituições de ensino superior público do Mestrado em Ensino de História e de Geografia $(\mathrm{MEHG})^{1}$, apurou-se que o segundo ano deste curso foi frequentado, no ano letivo de 2013/2014, por 63 alunos, valor que representa o total de efetivos do universo populacional dos professores de História e de Geografia em formação inicial (Quadro II).

Quadro II - Professores formandos de História e Geografia, segundo a instituição de ensino superior

\begin{tabular}{c|c|c|c|c|c|c}
\hline Instituição & $\mathrm{IE}$ & $\mathrm{FL}$ & $\mathrm{FL}$ & $\mathrm{FL}$ & FCSH- \\
& UMinho & UPorto & UCoimbra & ULisboa/IGOT & UNLisboa & Total \\
\hline N.o de alunos & 12 & 24 & 12 & 8 & 7 & 63 \\
\hline
\end{tabular}

\subsection{Amostragem}

Para selecionar o subconjunto de professores de Geografia do EBS a inquirir, dever-se-ia recorrer a um processo de amostragem ${ }^{2}$ que permitisse delimitar o número de inquiridos. Contudo, neste caso, considerou-se não ser viável a operacionalização de um método de amostragem. As razões que concorrem para este facto prendem-se com a indisponibilidade de estatísticas atualizadas relativas ao efetivo populacional e suas características, bem como com a inexistência de um registo da população que constitua uma base de amostragem ${ }^{3}$, a partir da qual se selecionem elementos para a amostra e se tenha acesso a referências sobre os mesmos.

A estratégia encontrada para contornar esta situação passou pela opção de tentar contactar o maior número possível de elementos do público-alvo, recorrendo para tal às escolas

\footnotetext{
${ }^{1}$ Mestrado instituído pelo Decreto-Lei no 43/2007, de 22 de fevereiro, o qual regulamenta o regime jurídico da habilitação profissional para a docência na educação pré-escolar e nos ensinos básico e secundário, e que será desmembrado em Mestrado em Ensino da Geografia e Mestrado em Ensino da História no 3.o Ciclo do Ensino Básico e no Ensino Secundário, de acordo com o Decreto-Lei no 79/2014, de 14 de maio.

${ }^{2}$ Ghiglione \& Matalon (1995), Ferreira \& Campos (2009), Hill \& Hill (2009), Coutinho (2011) apresentam os diversos métodos de amostragem probabilísticos ou aleatórios e os métodos não probabilísticos ou não aleatórios, identificando as suas (des)vantagens. No campo dos web surveys, Couper (2000) identifica oito tipologias, cinco das quais referem-se a web surveys baseados em probabilidades. Note-se que só é possível proceder à inferência estatística de resultados quando a amostra é probabilística, pelo que metodologias de inquérito não-probabilísticas condicionam os esforços de generalização de conclusões à população.

${ }^{3}$ Registo da população (listas, mapas, etc) de onde é retirada a amostra (Ferreira \& Campos, 2009).
} 
básicas e secundárias públicas do país, nomeadamente às direções/conselhos executivos, a quem se solicitou o reencaminhamento do questionário aos docentes de Geografia afetos às suas instituições.

Esta opção metodológica faz com que o estudo incorra nas técnicas amostrais não probabilísticas ou não aleatórias, em que não é possível especificar a probabilidade de um sujeito pertencer à população em estudo. Num contexto em que os participantes são selecionados de forma não aleatória, a questão da representatividade da amostra não está assegurada na sequência de um erro amostral de base (Coutinho, 2011). Tal como referem Ferreira \& Campos (2009: 61), nos métodos não probabilísticos não há "uma teoria estatística de suporte à obtenção de amostras representativas, mas pode existir uma probabilidade significativamente elevada de que a amostra obtida seja representativa". Sendo a amostragem uma questão sensível, Ghiglione \& Matalon (1995) alertam para o facto de não existir forma de assegurar a representatividade absoluta, aconselhando os investigadores a evitarem purismos excessivos em torno dos inevitáveis enviesamentos subjacentes à constituição de uma amostra e tendo presente que o mais importante é a adequação da amostra aos objetivos estabelecidos.

Por seu turno, no caso dos professores formandos de História e de Geografia, por se tratar de um público-alvo reduzido e de contacto fácil, considerou-se viável tentar inquirir toda a população. Também se sentiu receio de, ao implementar um procedimento de amostragem, incorrer no risco de o retorno ${ }^{4}$ dos questionários ser reduzido, dado ser comum haver discrepância entre a amostra planeada e a amostra obtida, decorrente das não respostas de indivíduos selecionados no processo de amostragem. Como Coutinho (2011) alerta, uma amostra demasiado pequena, ainda que obtida de modo probabilístico, também compromete a qualidade informativa dos dados recolhidos.

Face a todos os constrangimentos expostos, os respondentes ao inquérito "AS TIG no ensino de Geografia", são compostos por um painel de voluntários conseguidos de forma não probabilística, próxima de uma amostra de conveniência (Hill \& Hill, 2009), pelo que é necessário cuidado extra na validação dos resultados.

\footnotetext{
4 Índices de retorno da ordem dos 60\% a 70\% são indicados em Coutinho (2011) como aceitáveis.
} 
As opções disponíveis para a avaliação da dimensão da amostra obtida de modo não aleatório passam por assumir como referência uma dimensão usada anteriormente em estudos afins ou partir do princípio que a amostra é aleatória e avançar para a determinação da sua dimensão, calculando-se um valor apenas de referência (Weiers, 1998, apud Ferreira \& Campos, 2009). No presente estudo, recorrer-se-á à segunda opção.

\subsection{O questionário: secções, questões, respostas e suas escalas de medida}

Ultrapassada a questão de quem inquirir, iniciou-se a preparação do levantamento de dados, processo que neste survey decorre da aplicação de um inquérito por questionário autoadministrado. A inexistência de um instrumento de inquirição estandardizado levou à necessidade de construir um questionário, processo que, segundo Coutinho (2011), pode inclusivamente ser visto como integrante da própria investigação. Note-se que a formulação cuidada de um instrumento de inquirição é de suma importância para que a investigação seja bem-sucedida, pois condiciona a qualidade da informação recolhida, a metodologia de análise de dados e, por extensão, as conclusões do estudo.

A estruturação geral do inquérito por questionário "As TIG no ensino da Geografia" aplicado aos docentes de Geografia e aos professores formandos de História e de Geografia é similar, havendo, no entanto, algumas questões adaptadas à realidade e à experiência dos diferentes públicos em estudo. Estruturado em seis secções, o questionário foi formulado de modo a permitir aferir o nível de conhecimentos sobre as ferramentas TIG, as atitudes, os pareceres e as avaliações que os docentes fazem das TIG enquanto recurso educativo, bem como os fatores que promovem um clima (des)favorável à inclusão destas ferramentas nas práticas escolares (Quadro III). 
Quadro III- Estrutura do inquérito por questionário

\begin{tabular}{|c|c|c|c|c|c|c|c|c|c|c|}
\hline & & & As TIC & ensint & de Geo: & afia & & & & \\
\hline \multirow{3}{*}{ Secções } & \multicolumn{5}{|c|}{ Professores formandos } & \multicolumn{5}{|c|}{ Docentes em exercício } \\
\hline & \multicolumn{2}{|c|}{$\begin{array}{c}\text { Tipologia de } \\
\text { resposta }\end{array}$} & \multicolumn{3}{|c|}{$\begin{array}{c}\text { Escala de medida das } \\
\text { respostas }\end{array}$} & \multicolumn{2}{|c|}{$\begin{array}{c}\text { Tipologia de } \\
\text { resposta }\end{array}$} & \multicolumn{3}{|c|}{$\begin{array}{c}\text { Escala de medida das } \\
\text { respostas }\end{array}$} \\
\hline & Fechada & Aberta & $\mathrm{N}^{*}$ & $\mathrm{O}^{* *}$ & $\mathrm{M}^{* * *}$ & Fechada & Aberta & $\mathrm{N}^{*}$ & $\mathrm{O}^{* *}$ & $\mathrm{M}^{* * *}$ \\
\hline I- Perfil do inquirido & 7 & 1 & 4 & 1 & 2 & 8 & 0 & 5 & 1 & 2 \\
\hline $\begin{array}{c}\text { II - Formação em } \\
\text { TIG }\end{array}$ & 13 & - & - & 13 & - & 7 & 1 & 1 & 6 & - \\
\hline $\begin{array}{l}\text { III - Adequação das } \\
\text { TIG ao ensino }\end{array}$ & 11 & - & - & 11 & - & 11 & - & - & 11 & - \\
\hline $\begin{array}{l}\text { IV - Aplicabilidade } \\
\text { das TIG à Geografia }\end{array}$ & 11 & - & - & 11 & - & 10 & - & - & 10 & - \\
\hline $\begin{array}{c}\text { V- Usos escolares } \\
\text { das TIG }\end{array}$ & 8 & 1 & - & 8 & - & 9 & 2 & - & 9 & - \\
\hline $\begin{array}{l}\text { VI - Condicionantes } \\
\text { à inclusão das TIG }\end{array}$ & 23 & 1 & - & 23 & - & 23 & 1 & - & 23 & - \\
\hline \multirow{2}{*}{ Total } & 73 & 3 & \multirow{2}{*}{4} & \multirow{2}{*}{67} & \multirow{2}{*}{2} & 68 & 4 & \multirow{2}{*}{6} & \multirow{2}{*}{60} & \multirow{2}{*}{2} \\
\hline & \multicolumn{2}{|c|}{76} & & & & \multicolumn{2}{|c|}{72} & & & \\
\hline
\end{tabular}

O questionário é antecedido por uma breve nota introdutória, onde consta, de forma sucinta, tal como indicado por Hill e Hill (2009: 162): o pedido de colaboração no preenchimento, a justificação da aplicação do instrumento, a descrição do questionário, a instituição onde decorre a investigação e a declaração de confidencialidade e de anonimato. A primeira secção do questionário visa a caraterização dos inquiridos, cujo perfil é traçado com base em dados biográficos, habilitações académicas e situação profissional. Note-se que, enquanto Hill \& Hill (2009) defendem que a caraterização do respondente deve constar no início, Thayer-Hart et al (2010) consideram que os dados pessoais do respondente devem ser solicitados na última secção do questionário. 
Com o intuito de enquadrar os respondentes no conjunto de ferramentas TIG, noção fundamental na problemática em estudo, a segunda secção do questionário foi orientada no sentido de os respondentes procederem a uma autoavaliação dos seus níveis de conhecimentos em TIG, avaliarem a necessidade sentida de efetuarem formação em TIG e indicarem a formação realizada neste domínio. Para evitar uma incorreta interpretação de conceitos mais técnicos, o uso de terminologia específica das ferramentas TIG foi sucedido por uma breve definição e enquadramento do tipo de tecnologia em questão, acompanhada pela exemplificação de programas ou serviços tidos como TIG. Foram, assim, seguidas as sugestões dadas por Thayer-Hart et al (2010) relativamente à importância de contextualizar e explicitar os conceitos chave e as questões numa espécie de preâmbulo.

Dado que a inquirição de aspetos mais específicos só deve ser realizada numa fase mais avançada do questionário (Thayer-Hart et al, 2010), apenas na terceira e na quarta secção os respondentes são confrontados com questões relacionadas com a adequação das TIG ao ensino e, em particular, ao ensino de Geografia. Deliberadamente, recorreu-se nestas secções ao uso de uma linguagem decalcada dos documentos orientadores do ensino da Geografia no terceiro ciclo e no ensino secundário.

A regularidade do uso das ferramentas TIG e os contextos educativos em que é feito esse uso são analisados na quinta secção do questionário, orientada para o conhecimento dos usos escolares das TIG.

A última secção do questionário é reservada à avaliação das condicionantes à inclusão das TIG enquanto tecnologias educativas, solicitando-se aos respondentes a avaliação do nível de des(adequação) de um amplo leque de fatores. O questionário finda com a possibilidade de os respondentes efetuarem uma avaliação global da temática em estudo.

Para facilitar a compreensão do inquérito, os assuntos com alguma proximidade temática estão agrupados na mesma secção. Teve-se o cuidado de agrupar os tópicos que apresentam modalidades de resposta similares, de forma a garantir a coerência e a consistência do instrumento (Ghiglione \& Matalon,1995; Thayer-Hart et al, 2010). De referir que, na opinião de Hill \& Hill (2009: 164), o agrupamento de questões em blocos temáticos adequa-se à recolha de factos, mas na recolha de opiniões, atitudes e satisfações poderá ser vantajoso não colocar as perguntas de uma secção num só bloco, de modo a minimizar os efeitos de memorização e a tendência de uso de um estilo de resposta repetitivo. 
É recorrente o alerta para que as questões sejam formuladas numa linguagem simples e isenta de ambiguidades e que abordem apenas um assunto.

A opção por questões de tipo abertas ou fechadas constituiu um sério dilema. Se, por um lado, as questões abertas viabilizam que o respondente se expresse livremente, manifestando a sua visão precisa sobre o assunto (Thayer-Hart et al, 2010), também é verdade que esta é uma tipologia de resposta mais complicada de codificar, e que apresenta um maior número tanto de não-respostas como de respostas desadequadas (Reja et al 2003), pelo que são questões que requerem um cuidado redobrado na sua formulação, sobretudo em questionários autoadministrados. Tanto Reja et al (2003) como Thayer-Hart et al (2010) corroboram a ideia segundo a qual, na perspetiva dos respondentes, as questões em que se disponibilizam alternativas de resposta são mais atrativas, por exigirem menos tempo de interpretação e de resposta.

Deste modo, por se pretender formular o questionário numa perspetiva facilitadora do preenchimento na ótica do inquirido, o número de respostas fechadas supera largamente as respostas abertas. A par de alguns itens de resposta binária, a generalidade das escalas de resposta ${ }^{5}$ está formulada de modo a que o respondente selecione o descritor que melhor traduz o seu grau de concordância/satisfação/importância/ adequação/frequência com o teor do item, inspiradas nas escalas de medição intervalar do tipo Likert. Compostas por cinco níveis gradativos, estas oscilam entre um polo negativo e um polo positivo, balanceados por um ponto neutro, exemplificada pela seguinte escala: discordo completamente, discordo, nem concordo nem discordo, concordo, concordo completamente. A opção pelo predomínio deste tipo de escala de medida deriva do rápido entendimento dos respondentes da modalidade de resposta pretendida, da facilidade de codificação das respostas e, ainda, das possibilidades de tratamento estatístico subjacentes. Deve-se referir, contudo, que o facto de na prática se tratarem de escalas ordinais ${ }^{6}$ disfarçadas de escalas métricas, o seu tratamento estatístico pressupõe alguma

\footnotetext{
${ }^{5}$ Em Hill \& Hill (2009) e em Coutinho (2011) são explanadas as escalas de medida subjacentes aos diferentes tipos de resposta fechada. Estes autores também sistematizam as técnicas estatísticas passíveis de aplicação às diferentes escalas de resposta em função das variáveis avaliadas.

${ }^{6}$ As escalas ordinais admitem uma ordenação numérica das suas categorias, estabelecendo uma relação de ordem entre elas, sem contudo ser possível medir a magnitude das diferenças entre categorias (Hill \& Hill, 2009: 108).
} 
flexibilização do rigor metodológico, dado que não há uma forma de garantir que a distância, entre um uso escolar das TIG "raramente" e "às vezes", é percecionada da mesma forma pelos respondentes.

Teve-se o cuidado em deixar espaço para que os respondentes se pudessem expressar livremente em relação ao papel das TIG no ensino de Geografia. Na tipologia de resposta aberta, impõe-se a análise de conteúdo como método de análise de dados antecedida de um processo de codificação das respostas.

Sabendo que a predisposição de colaboração dos respondentes no preenchimento do questionário é essencialmente condicionada pelo tamanho e layout do mesmo (Hill \& Hill, 2009), procurou-se cingir a um número de questões que permita recolher informação necessária, de acordo com os objetivos da investigação, e evitou-se a tentação de ser demasiado exaustivo, correndo o risco de dissuadir o respondente. Em termos gráficos, seguiram-se as indicações de Thayer-Hart et al (2010) e aplicou-se um layout simples e consistente.

\subsubsection{O questionário on line para docentes de Geografia}

A inexistência de uma listagem de docentes de Geografia do EBS e a impossibilidade de contactar diretamente com os potenciais respondentes, para além de representarem sérios constrangimentos à formulação de uma amostragem probabilística, determinaram que o questionário fosse formulado on-line e remetido por correio eletrónico a todas as escolas públicas do país onde funciona o terceiro ciclo do ensino básico e o ensino secundário, níveis para quais os professores de Geografia estão habilitados a lecionar. Considerou-se que os docentes de Geografia do EBS são uma das populações onde é exequível a implementação de uma modalidade de recolha de dados assente na web, pois acredita-se que neste conjunto populacional o acesso à internet é elevado e que é comum a existência de um endereço de correio eletrónico, até porque é prática recorrente a instituição escolar fornecer um email para fins profissionais.

A modalidade de inquérito por questionário adotada para a inquirição dos professores de Geografia em exercício enquadra-se nos electronic surveys, definidos por Jansen et al (2007: 2) como sendo aqueles em que o computador desempenha um papel de relevo, tanto na 
distribuição do inquérito aos potenciais respondentes, como na compilação/recolha de dados dos respondentes, em particular nos web-based survey, atendendo ao facto do instrumento se encontrar alojado num servidor web e ser acessível através de um navegador de internet (Green, 1995; Stanton, 1998, apud Jansen et al 2007). Considerou-se ser esta a modalidade de inquérito que melhor se ajustava aos moldes do estudo, na medida em que permitiria de um forma rápida e económica tentar chegar a um elevado número de potenciais respondentes, contando-se para tal com o reencaminhamento do pedido de colaboração no preenchimento do inquérito por partes das direções/conselhos executivos das escolas públicas portuguesas.

De entre as muitas opções disponíveis, selecionou-se a aplicação Formulário da plataforma de armazenamento de dados on-line Google Drive (https://drive.google.com) para a elaboração do inquérito. O Google Drive na web é compatível com as versões mais recentes dos navegadores de uso mais generalizado (Google Chrome, Internet Explorer, Firefox, Safari) e com os sistemas operativos Windows (Microsoft), OS X (Apple) e baseados em Linux (https://support.google.com/drive/answer/2375082?hl=pt-PT, acedido a 12/10/2013). Em relação à edição do questionário, o formulário do Google Drive disponibiliza ao utilizador um leque diverso de opções, desde aspetos organizacionais, tipologia de questões até ao próprio layout final (https://support.google.com/docs/answer/2839737, acedido a 12/10/2013), permitindo a estruturação do questionário de acordo com as orientações bibliográficas.

Utilizaram-se alguns artifícios disponíveis na edição do formulário on-line, nomeadamente a disponibilização ao respondente da monitorização do preenchimento do inquérito através da visualização de uma barra de progresso. A definição de obrigatoriedade de responder à maioria das questões foi uma estratégia adotada no sentido de evitar o não preenchimento de campos de resposta por distração. Entre as perguntas cujas respostas não são obrigatórias, estão as que solicitam a indicação de informação muito específica (ex: ano de conclusão da licenciatura, formações realizadas em TIG e respetivas entidades formadoras),

\footnotetext{
7 Para além da criação de inquéritos on-line, o editor de formulários do Google permite o registo e a visualização das respostas recebidas numa folha de cálculo, a qual incorpora ferramentas complementares de análise estatística de dados (https://support.google.com/docs/answer/87809?hl=PT, acedido a 12/10/2013). Oferece também a possibilidade de transferência dos dados, sendo possível a transferência dos dados em diversos formatos, como por exemplo xls, usado pelo Excel, programa de cálculo da Microsoft.
} 
atendendo a que os respondentes manifestam dificuldade em se recordar de datas ou acontecimentos detalhados (Thayer-Hart et al, 2010). Dado que os inquiridos são pouco propensos a responder a questões de resposta aberta (Reja et al, 2003), a resposta a esta tipologia de questão também ficou como optativa.

Não foram incorporadas ferramentas audiovisuais para não sobrecarregar as ligações de baixa velocidade, dado que a demora em carregar o formulário pode ser um fator de desistência do seu cabal preenchimento.

Uma última referência ao facto de se ter optado por, no corpo do email de divulgação do pedido de colaboração no preenchimento do questionário, se apresentar apenas o link de acesso ao instrumento, dado que a sua incorporação é aconselhável apenas para formulários com um reduzido número de questões (Couper, 2008 apud Thayer-Hart et al, 2010).

\subsection{Pré-teste}

Antes da implementação do questionário, deve-se testar a sua adequação aos objetivos do estudo através da aplicação em pequena escala da versão preliminar. Este procedimento, designado por pré-teste (Ghiglione \& Matalon, 1995), estudo preliminar (Hill \& Hill, 2009) ou estudo piloto (Coutinho, 2011), consiste na apresentação do instrumento a "um pequeno número de pessoas pertencentes às diferentes categorias de indivíduos que compõem a amostra" (Quivy \& Campenhoudt, 1998: 182), tendo em vista os ajustes finais do questionário para garantir o sucesso da investigação.

Para a realização do pré-teste do questionário dirigido aos docentes de Geografia, solicitouse a colaboração de um grupo restrito de docentes com atributos (género, idade, instituições onde adquiriram a qualificação profissional, vínculo profissional, área geográfica de docência) tendencialmente próximos ao perfil médio dos docentes de Geografia (DGEEC \& DSEE, 2013). No pré-teste do questionário formulado para os futuros professores de Geografia, contou-se com a colaboração de alguns professores formandos de História e de Geografia a frequentar o curso do Mestrado em Ensino da Faculdade de Letras da Universidade de Coimbra, no ano letivo de 2012/2013. Após o preenchimento individual do questionário, durante o qual se estimou o tempo de resposta, os docentes e futuros 
docentes envolvidos no pré-teste foram convidados a fazer uma apreciação global do mesmo, seguindo-se um momento de análise crítica das diferentes questões. Deste diálogo, foi possível verificar o domínio da terminologia relacionada com as TIG e aferir a necessidade de explicitação de alguns conceitos.

Os pareceres emitidos pelos respondentes na fase de pré-teste revelaram-se pertinentes e possibilitaram a deteção de insuficiências que permitiram produzir uma versão final do questionário mais consistente. Alterações na sequência das secções do questionário, reformulação/eliminação de algumas questões, adequação das modalidades de resposta e respetivas escalas de resposta são exemplos de reajustes feitos à versão inicial do questionário decorrentes das achegas apresentadas pelos respondentes no pré-teste. Particularmente no caso do questionário dirigido aos docentes de Geografia, por estar formulado on-line, a fase de pré-teste também serviu para verificar a exequibilidade desta modalidade de recolha de dados. Para tal, solicitou-se que os respondentes acedessem ao questionário a partir de diferentes tipos de navegadores web e de diferentes sistemas operativos, antecipando eventuais dificuldades em receber, abrir, preencher e submeter o questionário (Graeml \& Csillag, 2008; Thayer-Hart et al 2010).

Os resultados obtidos na fase de pré-teste foram codificados e submetidos a um tratamento estatístico simples. Para a avaliação da consistência interna do questionário, calculou-se o coeficiente alpha de Cronbach $^{8}$, adequado para avaliar a fidelidade ${ }^{9}$ de questionários formulados com escalas de tipo Likert. Os pareceres dos orientadores da investigação sobre o instrumento também coadjuvaram na validação do inquérito por questionário.

Testados o inquérito e os procedimentos de recolha de dados, e feitos os reajustes necessários, passou-se à recolha de dados, solicitando aos potenciais respondentes a sua colaboração no preenchimento do inquérito.

\footnotetext{
${ }^{8} \mathrm{O}$ coeficiente Alpha de Cronbach permite verificar quão consistentemente um item mede o mesmo que o instrumento total. Tendo por base as médias das correlações inter itens e o número de questões, é determinada em que medida o grau de variância geral dos resultados se associa ao somatório da variância de cada item. Quanto mais alto é o resultado maior é a fidelidade do instrumento (Coutinho, 2011).

9 Um instrumento diz-se fiável quando se obtém sistematicamente o mesmo resultado na medição determinada propriedade, independentemente das circunstâncias de aplicação (Thayer-Hart et al, 2010:6).
} 


\subsection{Processo de recolha de dados}

A logística da recolha de dados envolveu procedimentos muito distintos para os dois públicos em estudo.

No caso do inquérito dirigido aos docentes de Geografia do EBS, por envolver a inquirição de docentes em meio escolar, dada a sua divulgação a partir das escolas públicas, obteve-se a anuência do preenchimento do inquérito por questionário por parte da Direcção-Geral de Inovação e de Desenvolvimento Curricular/Direção Geral da Educação, dando assim cumprimento ao disposto no Despacho n. 15 847/2007, bem como das Direções Regionais da Educação dos Açores e da Madeira.

Recorreu-se ao levantamento dos endereços de correio eletrónico das escolas públicas com terceiro ciclo e ensino secundário na página da Direção-Geral dos Estabelecimentos Escolares (http://www.dgeste.mec.pt/index.php/escolas/pesquisa-de-agrupamentos, acedido a 11/01/2014), no portal da educação dos Açores (https://www.edu.azores.gov.pt/Paginas/EscolasContactos.aspx, acedido a 11/01/2014) e no portal das escolas da Madeira (http://escolas.madeiraedu.pt/EscolasdaRAM/tabid/11869/Default.aspx, acedido a 11/01/2014). Da pesquisa efetuada, obteve-se o contacto eletrónico de um total de 1264 escolas (1200 em território continental, 34 na RAA e 30 na RAM). Aquando do envio da mensagem de correio eletrónico, verificou-se que uma parte muito significativa dos contactos eletrónicos disponibilizados pela Direção-Geral dos Estabelecimentos Escolares estava desatualizada, pelo que houve necessidade de proceder a uma nova pesquisa dos mesmos diretamente nas páginas dos agrupamentos de escola/escolas não agrupadas. Houve ainda necessidade de contactar telefonicamente um número restrito de escolas, cujo contacto eletrónico não constava on-line.

Considerou-se o início do terceiro período como sendo um momento oportuno para se dar início à recolha de dados, pelo que, de 7 a 15 de maio, se procedeu ao envio de um email aos Diretores dos Agrupamentos de Escolas/Escolas não agrupadas de Portugal continental, aos presidentes dos Conselhos Executivos das escolas da RAA e aos Diretores das Escolas da RAM, aos quais se solicitava o reencaminhamento da mensagem aos docentes de Geografia afetos às escolas. Esta opção fez com que, a todas as limitações inerentes à investigação por questionário eletrónico, acresça o facto de não haver garantias do efetivo 
reencaminhamento email aos potenciais respondentes, por se estar a recorrer a intermediários.

O email enviado às escolas é composto por uma breve carta de apresentação, tendo-se o cuidado de proceder à identificação da investigadora, dos objetivos genéricos da investigação e da instituição onde a mesma está a ser desenvolvida. $\mathrm{O}$ acesso dos potenciais respondentes ao questionário eletrónico é garantido através da disponibilização do seu URL (Universal Resource Locators), para que, através de um clique com o rato sobre a hiperligação, seja feito o reencaminhamento para à página do questionário. Na parte final do email, para além do agradecimento, é dada indicação do tempo aproximado de resposta e alerta-se para a necessidade de se submeter o inquérito apenas uma única vez.

Com algumas escolas, estabeleceram-se individualmente contactos posteriores, no sentido de prestar esclarecimentos solicitados pelas direções, nomeadamente em questões relacionadas com a certificação de autorização para a aplicação do inquérito em meio escolar e da condição de aluna do curso de doutoramento em Geografia. Apesar de em número diminuto, algumas escolas tiveram o cuidado de confirmar o reencaminhamento do email aos docentes de Geografia.

Como estratégias para incrementar o número de respostas ao questionário, optou-se pelo envio de um lembrete ${ }^{10}$ após três semanas da divulgação do pedido de colaboração a todas as escolas dos concelhos dos quais ainda não se tinha obtido nenhuma resposta. Paralelamente, contou-se com a divulgação do questionário entre a lista de contactos de professores de Geografia de um docente do ensino superior e investigador na área do ensino em Geografia. $\mathrm{O}$ apelo ao preenchimento do inquérito foi feito após a primeira fase de divulgação do inquérito, a 22 de maio, e posteriormente a 18 de julho, no términus da fase de recolha de dados.

Por se tratar de um universo populacional muito mais restrito, a operacionalização do processo de recolha de dados junto dos professores estagiários de História e de Geografia não foi tão exigente. Contou-se com a cooperação de docentes do segundo ano do curso de MEHG das diferentes instituições de ensino superior público, a quem se solicitou

${ }^{10} \mathrm{O}$ envio de uma mensagem a relembrar o preenchimento do questionário é uma estratégia referenciada como frutífera, podendo ser efetuada algum tempo após o envio do convite ao preenchimento do inquérito (Graeml e Csillag, 2008) ou dias antes do fim do prazo de preenchimento (Thayer-Hart et al, 2010). 
autorização para aplicação do questionário numa das unidades curriculares lecionadas. No Instituto de Educação da Universidade do Minho (IEUM), na Faculdade de Letras da Universidade do Porto (FLUP) e na Faculdade de Letras da Universidade de Lisboa/Instituto de Geografia e Ordenamento do Território (FLUL/IGOT), a recolha de dados decorreu nas duas últimas semanas de aulas do primeiro semestre. Na Faculdade de Letras da Universidade de Coimbra (FLUC), optou-se por proceder à aplicação no início do segundo semestre, enquanto na Faculdade de Ciências Sociais e Humanas da Universidade Nova de Lisboa (FCSH-UNL) o preenchimento do questionário decorreu no final do ano letivo.

Cientes de que muito dificilmente se alcançaria o objetivo de auscultar todo o universo populacional, decidiu-se por, presencialmente, ou na impossibilidade de deslocação à instituição através do docente da unidade curricular, solicitar a cooperação no preenchimento do inquérito por questionário aos alunos numa aula de uma das unidades curriculares do curso de mestrado, tendo-se o cuidado de deixar exemplares para os alunos que se encontravam ausentes aquando da deslocação às instituições.

\section{A adesão ao questionário "As TIG no ensino de Geografia"}

O período de recolha de dados no sistema web-survey iniciou-se no dia 7/05/2014 e prolongou-se até ao dia 31/07/2014, data em que se desativou a receção de respostas na plataforma Google Drive. Durante este período contabilizou-se um total de 410 respostas submetidas pelos docentes de Geografia do EBS (Fig. 2).

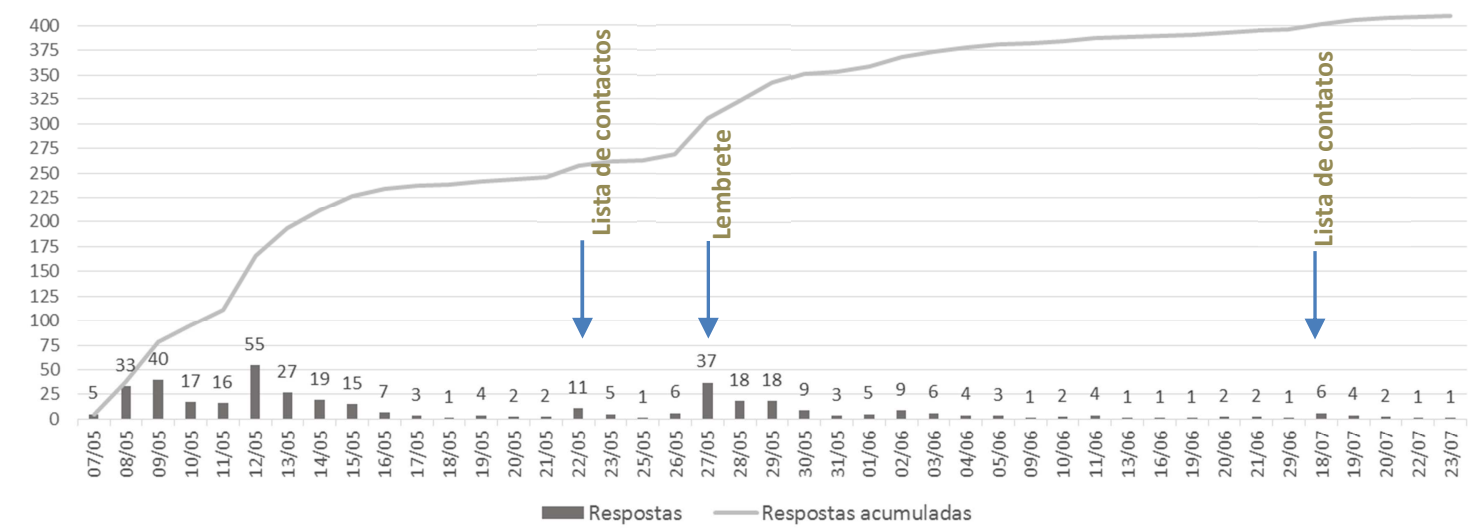

Figura 2 - Respostas submetidas ao inquérito por questionário "As TIG no ensino de Geografia" na plataforma Google Drive 
Verifica-se que a primeira semana após o envio do pedido de divulgação do questionário regista o pico máximo de submissão de respostas, dado que entre os dias 7 e 14 de maio foram submetidas $52 \%$ das respostas ao questionário. Estima-se que as estratégias usadas para aumentar a taxa de resposta tenham contribuído para a submissão de $25 \%$ das respostas, sendo particularmente evidente a importância do envio do lembrete às escolas dos concelhos em relação aos quais não se tinha obtido nenhuma resposta até ao dia 26 de maio.

Em termos de distribuição geográfica, foram recolhidos dados de docentes de Geografia que lecionam em $57 \%$ dos concelhos portugueses (Fig. 3).

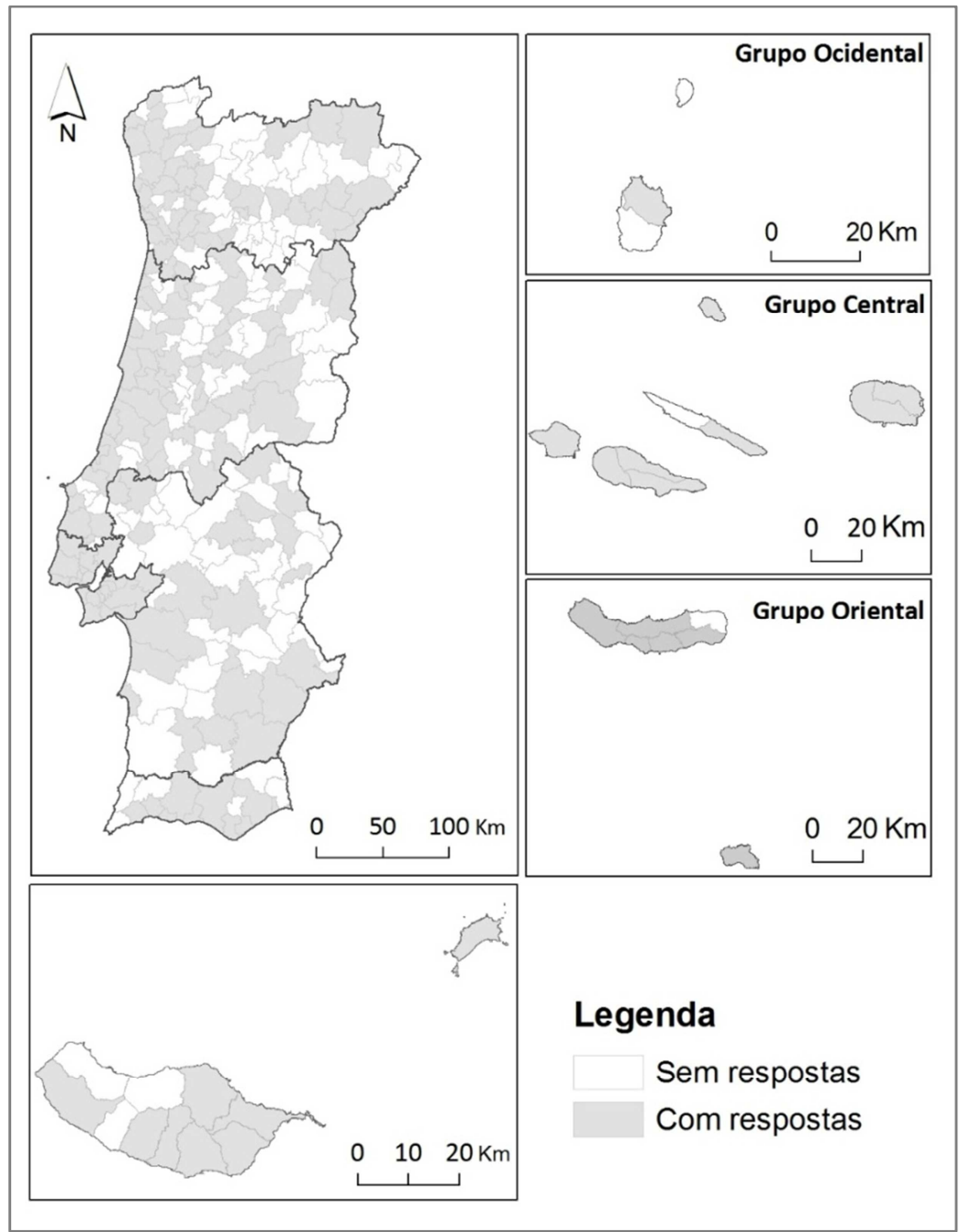

Figura 3 - Concelhos com respostas ao inquérito por questionário "As TIG no ensino de Geografia" docentes do ensino básico e secundário. 
A recolha de dados junto dos professores formandos de História e de Geografia, ao longo do ano letivo de 2013/2014, teve um retorno de 52 inquéritos. Face ao número de inquéritos preenchidos, a fração do universo dos futuros docentes de Geografia observada cifra-se nos 83\% (Quadro IV).

Quadro IV - Professores formandos de História e de Geografia respondentes ao questionário, segundo a instituição de ensino superior

\begin{tabular}{c|c|c|c|c|c|c}
\hline \multirow{2}{*}{ Instituição } & IE & FL & FL & FL & FCSH- & Total \\
& UMinho & UPorto & UCoimbra & ULisboa/IGOT & UNLisboa & \\
\hline Respondentes & 11 & 15 & 11 & 8 & 7 & 52 \\
\hline$\%$ & 91,7 & 62,5 & 91,7 & 100 & 100 & 82,5 \\
\hline
\end{tabular}

O envio de questionários preenchidos por alunos ausentes no momento em que foi aplicado o inquérito em situação de aula permitiu aumentar a taxa de respostas em cerca de $12 \%$.

Ainda que sendo resultados meramente indicativos da qualidade informativa dos dados, tomou-se por referência o procedimento utilizado no caso de amostragem probabilística para o cálculo da margem de erro e intervalo de confiança, tendo por base o número de respostas obtidas.

Para uma população de 4084 docentes de Geografia do EBS, a dimensão recomendada da amostra para obter uma margem de erro de $5 \%$ e um intervalo de confiança de $95 \%$ seria de 352 indivíduos (http://www.vsai.pt/amostragem.php, acedido a 31/07/2014). Tendo em conta que o número de professores de Geografia respondentes ao questionário foi de 410, a margem de erro desce para 4,6\% (https://www.checkmarket.com/market-researchresources/sample-size-calculator/, acedido a 31/07/2014).

Já para uma população de 63 professores formandos de História e de Geografia, a dimensão recomendada da amostra é de 55 indivíduos, para os dados terem um intervalo de confiança de $95 \%$ e uma margem de erro de $5 \%$. O número de respostas obtidas permite apenas um intervalo de confiança para $90 \%$, para o qual a dimensão recomendada da amostra é de 52 indivíduos, exatamente o número de elementos inquiridos (http://www.vsai.pt/amostragem.php, acedido a 31/07/2014). 
No Quadro V apresenta-se uma súmula da forma como se procedeu à operacionalização da aplicação do questionário "As TIG no ensino de Geografia".

Quadro V - Síntese dos procedimentos e dos resultados da aplicação do questionário

\begin{tabular}{|l|c|c|}
\hline “AS TIG no ensino de Geografia” & Docentes Geografia do EBS & $\begin{array}{c}\text { Professores formandos de } \\
\text { História e de Geografia }\end{array}$ \\
\hline População & $4084^{*}$ & 63 \\
\hline Questionário autoadministrado & Formulário on-line & Suporte papel \\
\hline Pré-teste & $01 / 2014$ & $12 / 2012$ \\
\hline Distribuição & Correio eletrónico & Presencial \\
\hline Período de recolha de dados & $05 / 2014$ a $07 / 2014$ & $12 / 2013$ a $05 / 2014$ \\
\hline Inquéritos preenchidos & 410 & 52 \\
\hline Taxa de amostragem & $10 \% * *$ & $82,5 \%$ \\
\hline
\end{tabular}

* Em 2013/2014

**A fração de docentes de Geografia do EBS auscultada é uma estimava, dado que tem por base dados do universo população no ano letivo anterior ao da aplicação do inquérito.

\section{Conclusões}

As opções metodológicas tomadas para implementar o inquérito por questionário "As TIG no ensino de Geografia" foram o resultado da tentativa de respeitar os procedimentos implícitos à investigação por survey, superar os constrangimentos associados a esta metodologia e adequar os procedimentos de aplicação de um questionários atendendo às particularidades do público-alvo.

As principais fragilidades da metodologia adotada decorrem da dificuldade de implementar um processo de amostragem aleatório, na medida em que este permitiria, com uma margem de erro calculável e um grau de confiança estimado, a extrapolação de conclusões após a análise dos dados recolhidos. Infelizmente, na operacionalização do questionário não foi possível respeitar estas premissas, em virtude do desconhecimento do total de efetivos e da inexistência de uma forma de contacto direto com o público-alvo no caso dos docentes de Geografia em exercício. No caso dos futuros professores de Geografia, pelo facto de se estar na presença de um grupo tão restrito de efetivos populacionais, considerou-se mais seguro tentar obter o máximo de respostas ao questionário, em vez de se constituir uma 
amostra, dado que muito provavelmente os resultados obtidos ficariam enviesados pelas não respostas.

Considera-se que as frações dos docentes de Geografia observadas são significativas, tanto no caso dos professores do EBS, como no caso dos professores formandos, pelo que se considera que os resultados do estudo sobre o papel das TIG no ensino de Geografia terão pertinência, ainda que não haja garantias da representatividade dos respondentes. Em relação aos professores de Geografia em exercício, a análise de dados estatísticos relativos ao perfil do docente de Geografia do ano letivo 2013/2014 permitirá avaliar de forma mais consistente a representatividade dos respondentes ao questionário.

\section{Referências}

Costa, C. M. M. O. d. F. (2011). A formação do cidadão geograficamente competente - aspectos da mudança de paradigma pedagógico em Didáctica da Geografia. Tese de Doutoramento, Faculdade de Letras Universidade do Porto.

Couper, M. P. (2000). "Web Surveys: a review of issues and approaches." Public Opinion Quarterly 64: 464-494.

Couper, M. P. e P. V. Miller (2008). "Web Survey Methods." Public Opinion Quarterly 72(5): 831 - 835.

Coutinho, C. P. (2011). Metodologia de Investigação em Ciências Sociais e Humanas, Edições Almedina, 344 p.

Decreto-Lei n. 43/2007 de 22 de fevereiro, Habilitação profissional para a docência, Diário da República, 1.ạ série-N.o 38-22 de Fevereiro de 2007.

Decreto-Lei n. 79/2014 de 14 de maio, Habilitação profissional para a docência na educação pré -escolar e nos ensinos básico e secundário, Diário da República, 1.a série - N. 92 - 14 de maio de 2014.

Despacho n. 15 847/2007, Aplicação de inquéritos em meio escolar, Diário da República, 2.a série-N. 14023 de Julho de 2007.

DGEEC e DSEE (2013). Estatísticas da Educação 2011/2012. Lisboa, 262 p.

DGEEC e DSEE (2014). Estatísticas da Educação 2012/2013. Lisboa, 288 p.

Díaz de Rada, V. e J. A. Domínguez-Álvarez (2014). "Response quality of self-administered questionnaires: A comparison between paper and web questionnaires." Social Science Computer Review 32(2): 256-269.

Esteves, M. H. M. d. B. F. (2010). Os percursos da cidadania na geografia escolar portuguesa. Tese de Doutoramento, Faculdade de Letras da Universidade de Lisboa.

Ferreira, M. J. e P. Campos (2009). O Inquérito Estatístico: uma introdução à elaboração de questionários, amostragem, organização e apresentação dos resultados. Um mundo para conhecer os números. INE, ESTP and DREN. Lisboa, Instituto Nacional de Estatística: 214 p.

Ghiglione, R. e B. Matalon (1995). O Inquérito- Teoria e Prática Oeiras, Celta Editora, 370 p.

Graeml, A. R. e J. M. Csillag (2008). "E-Mail Survey com Formulário Anexado: Uma Alternativa para Coleta de Dados Off-Line pela Internet." Organizações em contexto 4(7): 35-58.

Hill, M. M. e A. Hill (2009). Investigação por questionário. Lisboa, Edicões SíLABO, 377 p.

Jansen, K. J., K. G. Corley e B. J. Jansen (2007). E-Survey Methodology Handbook of Research on Electronic Surveys and Measurements. R. A. Reynolds, R. Woods and J. D. Baker, IGI Global: 1-8. 
Lynn, P. (2013). Issues of Coverage and Sampling in Web Surveys for the General Population: An Overview. Web Survey Network opening conference, Londres.

Nicolaas, G., L. Calderwood, P. Lynn e C. Roberts (2014). "Web Surveys for the General Population: How, why and when?" National Centre for Research Methods: 22 p.

Quivy, R. e L. V. Campenhoudt (1998). Manual de Investigação em Ciências Sociais, Gradiva Publicações, 276 p.

Reja, U., K. L. Manfreda, V. Hlebec e V. Vehovar (2003). Open-ended vs Closed-ended Questions in Web Questionnaires. Developments in Applied Statistics. A. M. Anuška Ferligoj (Eds.). Ljubljana: 159-177.

Roberts, C. (2013). Participation and engagement in web surveys of the general population: An overview of challenges and opportunities. Web Survey Network opening conference.Disponível em: http://www.natcenweb.co.uk/genpopweb/documents/Theme-2-Participation-and-engagement.pdf, acedido a 04/12/2013.

Rome Declaration on Geographical Education in Europe, (2013) Roma, 1 pp.

Sheehan, K. B. (2001). "E-mail Survey Response Rates: A Review." Journal of Computer-Mediated Communication 6(2), Disponível em: http://dx.doi.org/10.1111/j.1083-6101.2001.tb00117.x, acedido a 04/12/2013.

Solomon, D. J. (2001). "Conducting web-based surveys." Practical Assessment, Research \& Evaluation 7(19), Disponível em: http://pareonline.net/getvn.asp?v=7\&n=19, acedido a 05/05/2013.

Thayer-Hart, N., J. Dykema, K. Elver, N. C. Schaeffer e J. Stevenson (2010). Survey Fundamentals - A guide to designing and implementing surveys, Office of Quality Improvement 20 p. 